\title{
Los retos de la organización y transparencia en el Archivo Histórico de Jalisco
}

\author{
María Teresa Fernández Aceves
}

Este artículo aborda de manera sucinta cuáles fueron los antecedentes, cuándo y cómo se creó el Archivo Histórico de Jalisco; qué acervos lo conformaron; qué se hizo para su rescate y organización; el archivo en sí y la producción del conocimiento de la historia; qué se ha legislado y los problemas vigentes en torno al acceso, organización, legislación y los retos que conlleva llevar a cabo la Ley de Transparencia en los archivos públicos.

PPALABRAS CLAVE: archivos históricos, transparencia, acceso, organización, rescate

\section{Challenges of Organization and Transparency in the Historical Archive of Jalisco}

This paper addresses the origins of the Historical Archive of Jalisco: when and how it was created; which collections comprise the archive; its organization and preservation; the production of historical knowledge; which laws have been passed; the current problems regarding access, organization and legislation; and finally, the challenges posted by the Federal Law of Transparency and Access to Public Government Information regarding public archives.

KEY WORDS: historical archives, transparency, access, organization, preservation

MARÍA TERESA FERNÁNDEZ ACEVES: Centro de Investigaciones y Estudios Superiores en Antropología Social-Occidente, Guadalajara, México

mferna1@mail.udg.mx 
$\mathrm{E}$ n un contexto de cambio democrático y de mayor participación ciudadana se promulgaron la Ley Federal de Transparencia y Acceso a la Información Pública Gubernamental (LFTAIPG) y la Ley de Transparencia e Información Pública del Estado de Jalisco (LTIPEJ) ${ }^{1}$ para facilitar el acceso a la información; transparentar la gestión pública; garantizar la protección de los datos personales; favorecer la rendición de cuentas, y mejorar la organización, clasificación y manejo de los documentos. Estos objetivos, creados en concordancia con la preocupación actual por contribuir a la democratización de la sociedad mexicana, se asemejan a inquietudes añejas sobre cómo guardar la información y cómo organizarla. En el centro de estas cuestiones han estado las interrogantes de cómo funcionan los archivos, qué guardan y cómo aproximarse a ellos para lograr un funcionamiento óptimo de la administración pública y atender las peticiones de la ciudadanía. Por tanto, el interés por mejorar la organización, la clasificación y el manejo de documentos no es nueva; lo que sí es novedoso es el reconocimiento a los derechos de la ciudadanía a solicidatos específicos. Sin embargo, para que los ciudadanos consigan la información solicitada en las unidades de enlace de las dependencias, su demanda está sujeta a una "descripción clara y precisa de los documentos" que solicite $^{2}$. Considero que allí reside un problema y un punto clave que dificultan la aplicación de estas leyes (LFTAIPG y LTIPEJ) porque la mayoría de los archivos — principalmente los históricos y de concentración - no siempre tienen actualizados sus índices, inventarios y catálogos. Cuando mucho, los encargados de estos acervos pueden saber qué fondos documentales tienen, pero no su contenido exacto.

\footnotetext{
${ }^{1}$ Ley Federal de Transparencia y Acceso a la Información Pública Gubernamental, Diario Oficial de la Federación, 11 de junio de 2002. Esta ley se reformó el 11 de mayo de 2004. En Jalisco, la primera Ley de Transparencia e Información Pública del Estado de Jalisco fue publicada en el Periódico Oficial El Estado de Jalisco el 22 de enero de 2002, mediante el decreto núm. 19446. Esta ley fue abrogada por el decreto 20867 y se creó otra el 6 de enero de 2005.

2 En la LFTAIPG véase el artículo $40^{\circ}$, inciso II, p. 13; en la LTIPEJ véase el artículo $62^{\circ}$, inciso III, p. 26.
}

Desde que México obtuvo la Independencia en 1821, la administración pública y la documentación que ésta ha generado han crecido y esta última se ha convertido en un monstruo difícil de manejar, controlar y conservar. A pesar de recomendaciones, circulares y reglamentos que subrayaron la necesidad e importancia de organizar los archivos, muchos tendieron a crecer sin orden, en espacios inadecuados y sin personal calificado. Ilustro estas acciones y problemas al enfocarme en el caso del Archivo Histórico de Jalisco (AHJ). Antes de emprender el análisis de los desafíos en este archivo, es importante presentar de manera sucinta cuáles fueron sus antecedentes, cuándo y cómo se creó, qué acervos lo conformaron, qué se hizo para su rescate y organización, qué se ha legislado y los problemas vigentes en torno al acceso, organización y transparencia. Esta reflexión permitirá ampliar el debate en este número de Desacatos sobre el acceso, organización, legislación y los retos que conlleva llevar a cabo la Ley de Transparencia en los archivos públicos.

\section{ANTECEDENTES DEL ARCHIVO HISTÓRICO DE JALISCO}

Con el establecimiento del estado de Jalisco en 1824 empezó la legislación sobre cómo funcionaría y reglamentaría el gobierno estatal. Para el buen funcionamiento de la nueva administración se nombró a un encargado del archivo de los expedientes de la Secretaría General de Gobierno (Colección de decretos, 1874: t. II, 412). En 1825, en un reglamento para el gobierno de la Secretaría se desglosaron las actividades del archivista: ordenar en un archivero los documentos sobre un mismo asunto; registrar los asuntos concluidos; llevar los libros de índices por orden alfabético especificando cuántos expedientes estaban archivados y cuántos en trámite; numerar los expedientes recibidos; elaborar un inventario de todos los decretos, órdenes, circulares y demás impresos existentes, los cuales debía engargolar para facilitar su consulta, y recibir de la imprenta los diarios del Congreso. Por ningún motivo debía permitir la extracción de documentos sin expresa orden de los secretarios; si se diera el caso, se asentaría la razón y la firma de entrega (ibid., 1874: t. II, 6). 


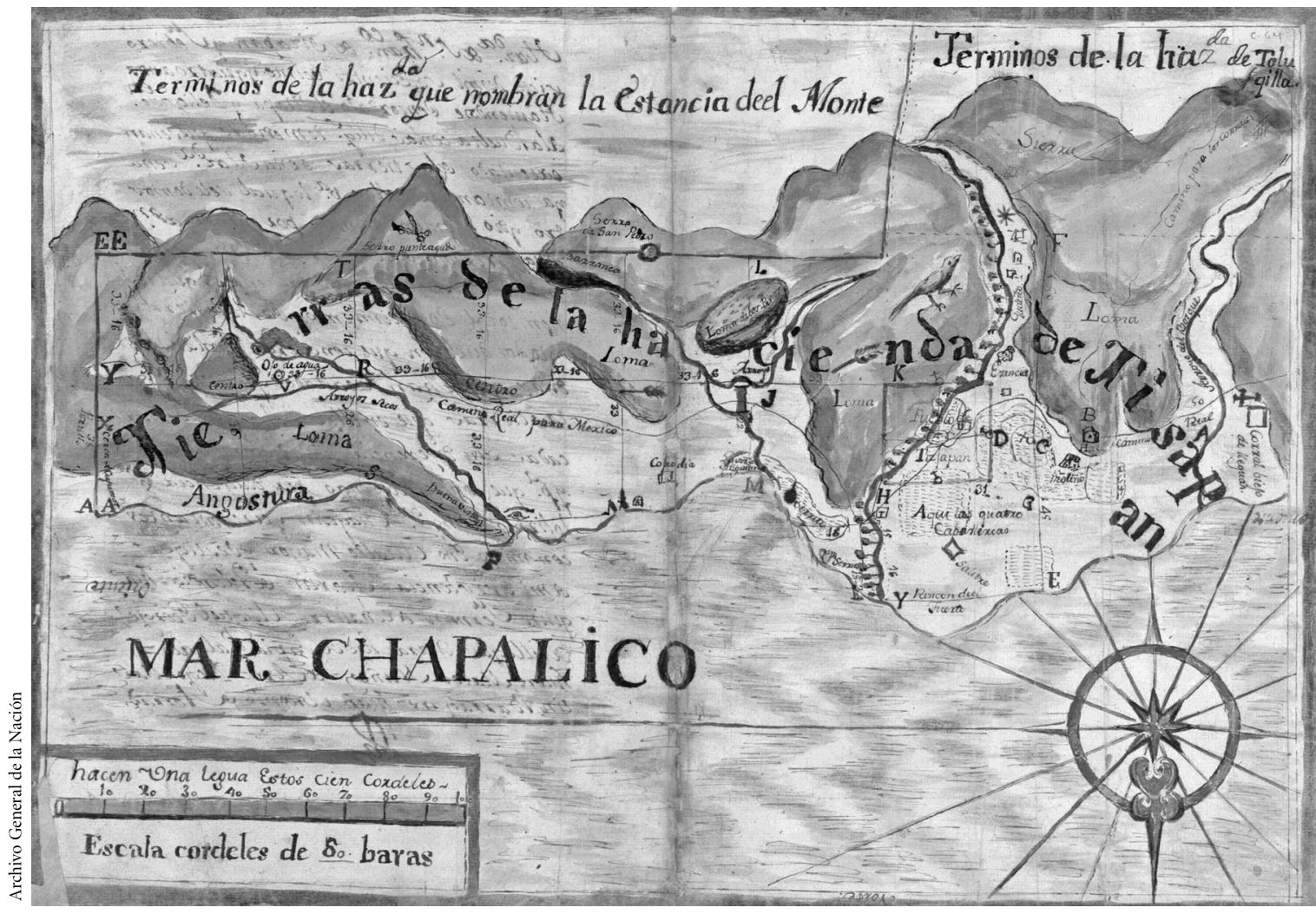

Hacienda de Tizapán, Sayula, Jalisco, 1792. Catálogo de ilustraciones, 2934, AGN.

$\mathrm{Al}$ igual que otros acervos del país, el archivo de la Secretaría General de Gobierno padeció los efectos de la inestabilidad política y de la guerra: "incendios, trashumancia, saqueo, y venta” (Rendón, 1979: 27). Por ejemplo, durante la Guerra de Tres Años (1854-1847), de sus quince batallas importantes, doce se libraron en Jalisco (Muriá, 1980: vol. 3, 207-233). En 1859, una explosión en el Palacio de Gobierno quemó gran parte de los documentos. Durante la Intervención francesa (1863-1867) este archivo "fue llevado por el Gobierno Constitucional a la campaña y lo que no se perdió del todo, se dispersó con gran peligro" (Rendón, 1979: 27). En mayo de 1867 se ordenó y resaltó la necesidad de arreglar los archivos de diversas oficinas de la Federación y de la entidad. Aquellas personas que habían sido funcionarios y que tuvieran documentos o libros del Estado, debían devolverlos. En caso de que algunas personas hubiesen destruido o desa- parecido documentos oficiales, serían arrestados (Colección de decretos, 1874: t. III, 321-322). Esta preocupación por tener ordenados y actualizados los archivos continuó en el siguiente decenio ${ }^{3}$. De acuerdo con Lina Rendón, el Archivo General de Gobierno fue reorganizado en 1873 y coincidió con "la publicación de la colección de leyes, circulares y órdenes dictadas por los poderes del Estado desde la erección de éste. Para 1886 se concluyeron los trabajos de rescate y organización del 'antiguo archivo', y ya en manos del historiador Manuel Cambre, el Archivo General de Gobierno tuvo un mejor funcionamiento" (Rendón, 1979: 28).

Para principios del siglo XX, desde el nivel federal se recomendó la conservación de los diversos acervos docu-

\footnotetext{
${ }^{3}$ AHJ, AR-2-874, Inv. 168.
} 
mentales del país y se dictaron prevenciones para evitar la destrucción de archivos ${ }^{4}$. En 1918, el gobierno federal encomendó a los gobernadores "la custodia de los archivos existentes en la Entidad [...] así como la reconstrucción e iniciación [de los mismos]" (Castañeda, 1981: 12).

Estos intentos de conservación y rescate no frenaron la venta de documentos a particulares o cartoneras (Aldana Rendón, 1979: 29). En 1940 algunos representantes de la Compañía Beneficiadora de Papel recorrieron el país para gestionar la adquisición de archivos de los gobiernos de los estados, ayuntamientos, obispados y parroquias "para utilizar el papel para fines industriales" 5 . La Secretaría de Gobernación sabía que en Jalisco se había rechazado la venta de los archivos, pero insistía en que se girara una circular a las dependencias de la entidad, ayuntamientos, encargados de obispados, parroquias y templos para que "por ningún motivo fueran vendidos los documentos antiguos, y que se conservaran en sus respectivas dependencias"6.

Esta preocupación por conservar y rescatar fondos documentales continuó en la década de 1950. Así, el profesor José Cornejo Franco, director de la Biblioteca Pública de Jalisco, rescató los archivos de la Audiencia, del Tribunal Superior de Justicia y de la Instrucción Pública de ser desechados. Los demás fondos documentales del antiguo Archivo General de Gobierno pasaron a una bodega que rentó la Tesorería General del Estado. De 1959 a 1973 no hubo personal encargado de organizar, depurar, inventariar y clasificar la información generada por las diferentes dependencias del Poder Ejecutivo estatal. Estos documentos fueron rescatados y puestos en cajas de 1973 a 1976 y transferidos para formar el AHJ en 1976.

Sin embargo, surge la pregunta: ¿por qué en esos años hubo interés y disposición política para establecer un archivo estatal del Poder Ejecutivo? Para el decenio de 1970 la documentación que se generaba en las dependencias gubernamentales, en especial las del Palacio de Gobierno, no podían albergarse en el mismo lugar donde se realizaban trámites. El crecimiento del volumen de los docu-

\footnotetext{
${ }^{4}$ Periódico Oficial, t. 80, 1914, p. 70.

5 AHJ, AR-2-940, Inv. 170

${ }^{6}$ Loc. cit.
}

mentos, la limitación de espacios y las irregularidades en la eficacia administrativa contribuyeron para que se lograra un cambio en torno a la idea y la función de los archivos: de lugares sólo para papeles muertos a áreas con "eficiencia tecnificada que pon[ía] al servicio colectivo lo que tantos años fue solamente hacinamiento inútil" (Rosas Benítez, 1977: II).

\section{EL ESTABLECIMIENTO DEL AHJ: LA ÉPOCA DE RESCATE, ORGANIZACIÓNY ACCESO}

Desde fines de 1973, la maestra Helen Ladrón de Guevara, junto con un equipo de profesionistas, empezaron a trabajar en la limpieza y ordenamiento de los documentos que se encontraban en la "bodega de papeles" de la calle Manzano. Los expedientes estaban en condiciones lamentables de abandono porque los traslados de legajos se hicieron en camiones de volteo, los choferes llegaban y tiraban la documentación al piso. Esta acción contribuyó a dispersar y desorganizar aún más los acervos de las oficinas?

De 1973 a 1976 se trabajó arduamente en el rescate, limpieza y ordenamiento. De manera simultánea se hizo un análisis de las memorias e informes de los gobernadores del estado de Jalisco de 1824 a 1976, con el objetivo de localizar los diversos asuntos tratados por la administración pública, ya que no se tenía una idea clara de qué contenía este acervo. Este estudio permitió tener un cuadro general del desarrollo de la administración pública en Jalisco y, por tanto, de los múltiples asuntos tratados. Se logró hacer una lista de los ramos que cubrían las diferentes oficinas gubernamentales. Los ramos y secciones identificados fueron: Archivo, Agricultura y Ganadería, Beneficencia, Estadística, Fomento, Gobernación, Hacienda, Instrucción Pública, Justicia, Trabajo, Periódico Oficial y Mapas y Planos. No todos los ramos contenían material desde 1821. Algunos venían en línea directa de las instituciones coloniales, mientras que otros se gesta-

${ }^{7}$ Ladrón de Guevara, 1977; y Helen Ladrón de Guevara, entrevistada por la autora, 15 de febrero de 2007, Guadalajara, Jalisco. 
ron y establecieron en el transcurso de los siglos XIX y $\mathrm{XX}$, de acuerdo con el mismo desarrollo de la administración pública federal y estatal.

En la primera etapa de rescate se acomodaron por ramos aproximadamente unos 7000 paquetes. La siguiente fase fue determinar el sistema de clasificación y catalogación para este archivo. De acuerdo con Carmen Castañeda: "se formaron las tablas de clasificación que especifican los asuntos que cubre cada ramo, una especie de tesauros, que se perfeccionan y completan conforme avanza el trabajo de clasificación de los documentos" (Castañeda, 1980: II). El sistema de catalogación aplicado se conformó de acuerdo con las reglas de catalogación angloamericanas y además se tomó en cuenta el principio de procedencia.

En 1980, Castañeda y su equipo de trabajo elaboraron un documento interno de trabajo titulado Manual de procesos técnicos, producto de por lo menos cuatro años de trabajo. Con él se sistematizaron los diversos procedimientos técnicos que llevaba a cabo el AHJ en los procesos de recepción, clasificación, catalogación y circulación. Se estipuló que "los documentos cuya fecha [fuera] anterior a 1940 se clasificar[ían] por ramo, asunto y año. Los documentos de 1940 a la fecha ser[ían] clasificados por dependencias, asunto y año" (ibid., 1980: 2-3). Después de clasificar los documentos, se seleccionaban algunos para catalogarlos. Se elaboraron los siguientes catálogos: de autor, temático, geográfico, cronológico, de expediente y topográfico. Este sistema funcionó de 1976 a 1987.

¿Qué se obtuvo durante este periodo con este sistema? Principalmente el rescate y el ordenamiento de los expedientes por ramos, la edición de dieciséis números del Boletín del Archivo Histórico de Jalisco, un Manual de procesos técnicos (AHJ, 1980), y las siguientes publicaciones: Folleto de información y difusión del Archivo Histórico de Jalisco (AHJ, 1979a), Guía de los archivos históricos de Guadalajara (AHJ, 1979b); Catálogo de la exposición bibliográfica de Jalisco, 1970-1981 (AHJ, 1981); Organización municipal del estado de Jalisco (AHJ y SGG, 1982) y Guía de las memorias e informes de los gobernadores de Jalisco (AHJ y SGG, 1982), así como la elaboración de los catálogos del ramo Instrucción Pública y de la Mapoteca (AHJ,
2003, 2005) y el Índice de los Cedularios. Se catalogaron 10096 expedientes de los diferentes ramos y se realizaron los inventarios casi completos o terminados de los ramos Archivo, Beneficencia, Estadística y Fomento, además de avances en los ramos de Hacienda, Justicia y Trabajo. Aproximadamente 43000 expedientes fueron inventariados y se clasificaron alrededor de 80 000. Esta producción, organización y trabajo constante del archivo sirvió de base y ayuda para un gran número de investigaciones, cuyos frutos se dieron a conocer durante la década de 1980, entre las cuales las dos más importantes fueron Historia de Jalisco (Murià, 1980a) y Jalisco desde la Revolución (Aldana Rendón, 1987).

Además de estas publicaciones y de la elaboración de diferentes instrumentos de consulta, la doctora Castañeda también contribuyó a formar a nuevos investigadores dentro del AHJ, a quienes enseñó habilidades básicas que resultaron muy útiles para sus futuras investigaciones: clasificar, inventariar, catalogar, reseñar libros y elaborar índices temáticos y cronológicos. En especial, durante la gestión de Carmen Castañeda como directora del AHJ (1978-1985) el archivo se convirtió en una especie de laboratorio donde, quienes trabajaban cotidianamente en diferentes puestos, practicaban la selección y la organización de los diversos documentos y también aprendían sobre la historia de Jalisco, de Guadalajara y del occidente del país.

A partir de 1988 se intentó establecer un nuevo sistema de clasificación, ya que se consideró que el trabajo realizado en el AHJ, "después de más de diez años de trabajo, [era] raquítico” (Guzmán Sánchez, 1989: 4). Se valoró que acarreaba una serie de errores y contradicciones porque no respetaba el orden original que le habían asignado los(as) archivistas. En ese año se inició un programa experimental llamado "Identificación documental" con el fin de reconstruir el sistema archivístico usado al recibir el expediente. Se comenzó con el ramo de Gobernación, con una muestra de los años de 1911 a 1916. La documentación se ordenó cronológicamente y por series, y después se elaboraron los índices geográfico y temático. Se reconstruyó el orden original de los siguientes ramos: Gobernación, de 1911 a 1920; Justicia, de 1896 a 1920, y Hacienda, de 1880 a 1920. De acuerdo con Ra- 


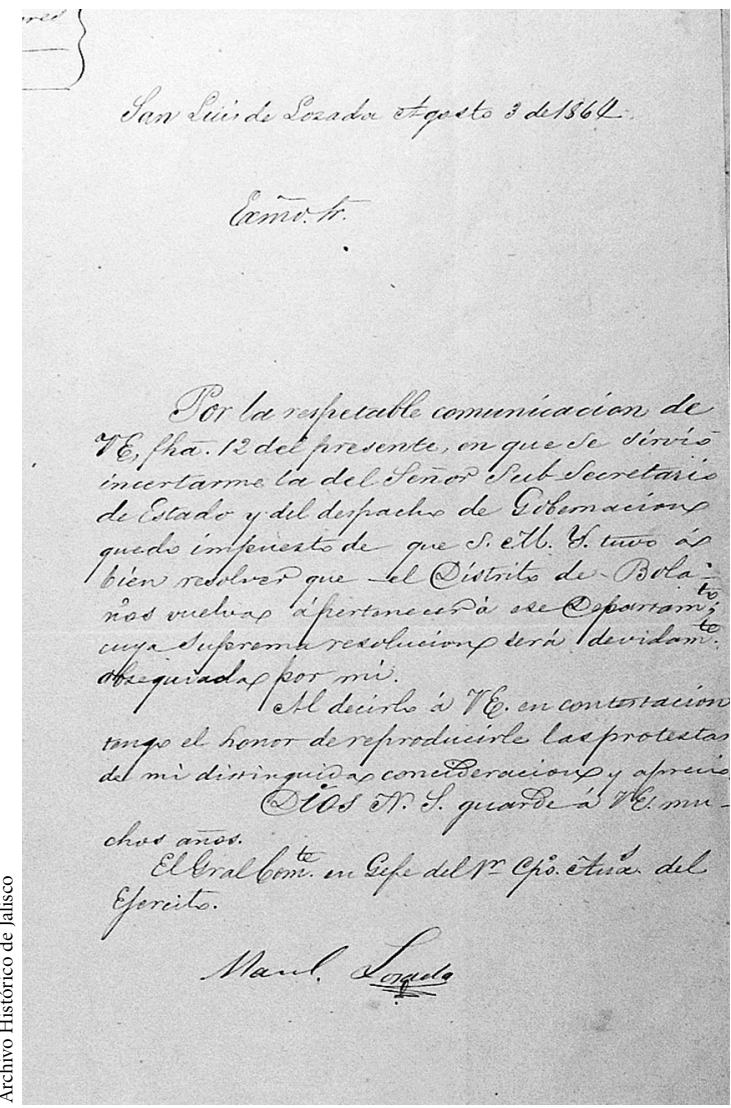

Carta de Manuel Lozada. AHJ, Ramo de Gobernación, G-5-864 BO/ 3478 .

fael Guzmán Sánchez, quien fue jefe de Procesos Técnicos del AHJ, trabajaron con 600000 documentos (ibid., 1989: 7). Se contrastó el trabajo realizado en el AHJ de 1976 a 1987 y el iniciado en 1988. De acuerdo con este cotejo, el trabajo de la primera etapa sólo representaba $10 \%$ del total. Se pensó que con esta nueva técnica se lograría superar el rezago en la organización del acervo y la elaboración de índices. Sin embargo, la identificación documental permitió sistematizar los documentos en su orden original, pero no se elaboraron inventarios ni catálogos, ni un nuevo manual de procedimientos técnicos que supliera técnicamente al anterior.

Un buen resultado de este experimento fue la organización numérica del expediente en su orden original, pero se desconocía el contenido preciso de los legajos, só- lo se sabía su clasificación de cuando fueron archivados. No se resolvió, así, el retraso en la organización y la elaboración de instrumentos de consulta. De los archivistas que participaron en el rescate y organización en 1973, para 1992 solamente estaba laborando uno; de los catalogadores que participaron en la elaboración de índices, inventarios y catálogos entre 1976 y 1987, sólo quedaban dos. Esta movilidad del personal ha sido un elemento importante que ha dificultado dar continuidad a ciertas políticas archivísticas.

De 1992 a 1993 fue un periodo de evaluación, transición y ajustes. Entre las tareas prioritarias estuvo la actualización del Manual de procedimientos técnicos de 1980, la capacitación del personal y la difusión de los catálogos. De 1994 a 1997 se continuó con ambas técnicas para organizar los fondos documentales. A partir de 2001 se decidió únicamente continuar con el Manual de procesos técnicos y aplicar algunos lineamientos de la Norma Internacional General de Descripción Archivística, ISAD (G) (AGN, 1997).

La tarea de elaborar instrumentos de consulta se ha entorpecido con las custodias y transferencias de otros acervos estatales. Desde su establecimiento en 1976 a la fecha, el archivo ha recibido en custodia o traspaso 21 archivos. Cabe señalar que no todos han sido parte de alguna dependencia del Poder Ejecutivo Estatal ${ }^{8}$. La gran mayoría de estas entregas se hicieron con un índice o inventario; sin embargo, éstos no siempre están a disposición de los usuarios del AHJ. Además de esos acervos, los fondos documentales actuales del AHJ son: Nueva Gali-

\footnotetext{
${ }^{8}$ Los acervos transferidos han sido los siguientes: Archivo de la Procuraduría General de Justicia, Archivo del Supremo Tribunal de Justicia, Archivo de la Junta Local de Conciliación y Arbitraje del Estado de Jalisco, Archivo del Departamento Médico Forense, Archivo de Acatlán de Juárez, Dirección de Pensiones del Estado, Archivo del Periódico Oficial, Archivo del Reclusorio Preventivo de la Zona Metropolitana, Archivo del Registro Civil, Archivo del Hospital Civil, Archivo de Oficialía Mayor de Gobierno, Archivo de la Sección de Correspondencia, Archivo del Departamento de Bellas Artes, Archivo de la Subsecretaría para Asuntos Jurídicos, Archivo del Departamento Jurídico, Archivo del Departamento del Trabajo, Archivo del Desarrollo Integral de la Familia, Archivo de la Comisión de la Costa, Archivo Escolar Archivo Histórico de Instrumentos Públicos, así como los Archivos de los Juzgados de lo Cuarto Civil, Hacienda y Penal. Para una detallada descripción de las transferencias de archivos, véase Castañeda, 1982: 20-21.
} 
cia (1573-1823), Agricultura y Ganadería (1833-1949), Beneficencia (1824-1966), Estadística (1840-1964), Fomento (1843-1971), Gobernación (1823-1980), Hacienda (1700-1975), Instrucción Pública (1824-1974), Justicia (1828-1975) y Trabajo y Previsión Social (1889-1980). Para febrero de 2007 contaba con un volumen de 60281 cajas, pero sin un inventario general de todos los acervos 9 .

Desde 1979, el AHJ se unió al programa del Registro $\mathrm{Na}$ cional de Archivos, iniciado por el Archivo General de la Nación. De ese año a la actualidad se ha continuado con el padrón censal de archivos municipales, estatales, de la administración pública y de archivos parroquiales. Sin embargo, estos índices no se han publicado y sólo han sido usados de manera interna. En enero de 2003, por acuerdo del gobernador, se creó el Sistema Estatal de Documentación de Archivos Públicos (SEDAP), con base en la Ley que Regula la Administración de Documentos Públicos e Históricos del Estado de Jalisco (LRADPHEJ) de 1998 para normar el funcionamiento de los archivos históricos y generales, elaborar un registro de los archivos municipales, señalar directrices para homologar los criterios de organización documental, participar de manera conjunta con los municipios para el rescate de sus archivos, elaborar un directorio estatal de archivos, brindar capacitación archivística y establecer instrumentos y mecanismos de consulta para facilitar el acceso a la información públi$\mathrm{Ca}^{10}$. El establecimiento del SEDAP puntualiza las atribuciones y los lineamientos de la política estatal en torno a los archivos, pero en la práctica ha sido difícil unificar y coordinar las diversas técnicas archivísticas que se han utilizado tanto en el AHJ como en los demás acervos estatales. En concreto, no se han llevado a cabo todas las disposiciones legales del SEDAP. Todo esto dificulta el acceso y la organización de la información pública.

Otro de los graves problemas es el cambio de directores y de personal. Esto ha provocado que, en algunas ocasiones, se desconozca y se pierda el trabajo realizado en años anteriores; por ejemplo, índices y catálogos que ya

\footnotetext{
${ }^{9}$ Susana Pacheco, entrevistada por la autora, 15 de febrero de 2007, Guadalajara, Jalisco.

10 "Acuerdo del ciudadano gobernador constitucional del estado libre y soberano de Jalisco, del 7 de enero de 2003"; publicado el 25 de febrero de 2003.
}

se habían elaborado. A partir de 2001 se inició la elaboración o reconstrucción de algunos índices y catálogos; el caso que mejor ejemplifica esto, es el ramo de Instrucción Pública. Al terminar su gestión, Carmen Castañeda dejó finalizado este catálogo, sólo faltaba su publicación, pero debido al cambio de directores se perdió este instrumento. La tarea de verificación y cotejo de los índices, catálogos e inventarios con lo que realmente existe en las cajas de documentos ha sido una tarea ardua y muy lenta. En este momento, los inventarios actualizados y cotejados sólo están disponibles para uso interno. Únicamente se han publicado los catálogos de la mapoteca (AHJ, 2003, 2005). Respecto a los archivos en custodia o transferidos, en muchos casos sí existe un índice o inventario, pero no han sido publicados. En algunos casos se debe obtener una autorización externa al AHJ para consultarlos. Este es el caso del Archivo Escolar: la Secretaría de Educación en el nivel estatal debe aprobar el acceso a la información.

A pesar de estas dificultades y problemas, cualquier persona puede tener acceso al AHJ llenando una ficha de registro, presentando su credencial del IFE y una carta que especifique la investigación que realizará. La consulta del acervo, mapoteca y biblioteca es de préstamo interno. Se permite la reproducción de los materiales sólo si están en buenas condiciones de conservación. Las restricciones para consultar parte del acervo se aplica en los siguientes casos: cuando el estado de conservación no permite el contacto manual directo, cuando está en proceso de fumigación, cuando forma parte de una exposición, cuando es de reciente ingreso y no está debidamente organizado, y cuando se necesite autorización de la dependencia que lo generó ${ }^{11}$.

\section{EL AHJY LA PRODUCCIÓN DEL CONOCIMIENTO DE LA HISTORIA}

En tanto que archivo del Poder Ejecutivo, el AHJ es una fuente documental histórica muy rica para estudiar dife-

\footnotetext{
$11<$ http://archivohistorico.jalisco.gob.mx/index.html $>$.
} 
rentes aspectos de la vida social, política, cultural y económica de Jalisco y la región occidente del país. Contiene datos del estado de Colima, en especial del puerto de Manzanillo en relación con la entrada de mercancías y el control de enfermedades. Asimismo, es un acervo fundamental para reconstruir la historia de Nayarit en el siglo XIX. Después de la independencia, en 1824, el estado de Jalisco incluía el Séptimo Cantón de Tepic. Éste fue parte de esta entidad hasta que se creó el Territorio de Tepic en 1884 (Meyer, 1997).

Varios historiadores interesados tanto en la historia de Nayarit como en las movilizaciones campesinas del siglo XIX han estudiado la rebelión de Manuel Lozada (18281873). En los informes militares de 1853, Lozada fue descrito como un terrible bandido, pero fue en verdad un precursor de las luchas campesinas y buscó la autonomía de la zona que controlaba: el cantón de Tepic. Intentó que los pueblos poseyeran los terrenos que les correspondían de acuerdo con sus títulos de tierras. Esta postura provocó disputas con varias haciendas porque devolvió tierras a pueblos que las habían perdido entre 1750 y importancia y fuerza durante los años de 1855 y 1856, cuando formó una alianza con las familias conservadoras Rivas y Barrón, que disputaban el control de San Blas y Tepic a los liberales, y con la familia Castaños. Lozada recibió apoyo económico para cubrir los gastos de compra de armas y para pagarle a sus soldados. Sin embargo, esta coalición duró poco, pues Lozada también afectó las posesiones de terrenos de estas familias. Los documentos que se catalogaron para el Boletín del Archivo Histórico de Jalisco de enero a abril de 1983 sirvieron como fuentes para publicaciones sobre este líder y para dar a conocer el Plan de Lozada, que pretendía tomar Guadalajara en 1873 (Aldana Rendón, 1983; Calvo y Meyer, 1989; Meyer, 1989a, 1989b, 1990, 1997; Rodríguez García, 1983).

A pesar de que no se han elaborado los índices, inventarios y catálogos completos de toda la información que alberga el archivo, los catálogos para el Boletín del Archivo Histórico de Jalisco sobre la mujer, educación, trabajadores, salud, comercio y comunicaciones, contribuyeron a la recuperación de la historia de Jalisco de las décadas de

1820 a 1940. La producción del conocimiento de la historia se ha realizado a través de muchas tesis de licenciatura, maestría y doctorado, de programas nacionales e internacionales, pero no siempre se han publicado. Respecto a lo que se ha publicado y se ha avanzado, seleccioné algunas temas y los contrasté con la sección "¿Qué se investiga en el Archivo Histórico de Jalisco?” del Boletín del Archivo Histórico de Jalisco. Esta revisión me dio indicios de los problemas históricos más recurrentes que han sido objeto de estudio. El asunto que más se ha investigado es el relacionado con la educación. Durante la gestión de Carmen Castañeda (1978-1984) se elaboró el catálogo completo del ramo de Instrucción Pública. Este instrumento de consulta ayudó a examinar asuntos sobre los tipos y métodos de enseñanza (Cárdenas, 1987; García Alcaraz, 1993), la formación de profesores (Ayala, 1994; Cárdenas Castillo y Pío Martínez, 1997; Peregrina, 1992), población escolar e instituciones educativas (escuelas primarias, Escuela de Artes y Oficios, Universidad de Guadalajara) (Cárdenas, 1999; Castañeda, 1995; De la Torre, 2000; Fernández Aceves, 1995; García, 1993; García e Ibarra, 2000; Peregrina, 1993) y política educativa (Dorantes González, 1993; García Alcaraz, 1997; Mercado Martínez, 1986; Peregrina, 1982).

Otro de los ejes abordados es el de los trabajadores y el movimiento obrero. Se ha investigado sobre las características del artesanado y los trabajadores en general en talleres y pequeñas, medianas y grandes industrias en áreas urbanas y rurales de Jalisco. Asimismo, se han puntualizado los orígenes e influencias del movimiento obrero en sus diferentes vertientes (anarcosindicalista, comunista, amarilla y católica), organizaciones, disputas, alianzas y su papel en la construcción del nuevo Estado mexicano después de 1917, la política laboral y su contribución al desarrollo económico y la estabilidad política (Alba Vega, 1980; Anderson, 1981; Fernández Aceves, 1991, 2003; Gabayet, 1988; Gómez Fragoso, 1980; González, 1981; Tamayo Rodríguez, 1985a, 1985b, 1987, 1988a, 1988b, 1988c; Tamayo Rodríguez y Valles, 1993).

Historiadores, antropólogos, sociólogos, economistas y arquitectos han confirmado que "Guadalajara ha sido la gran ciudad de la pequeña industria" y que han coexistido diversas formas de producción (artesanales e indus- 
triales) (Arias, 1985a). Guadalajara ha contrastado con la ciudad de México, que ha sido el foco central que agrupa a una gran cantidad de empresas y trabajos, y que ha reclutado, igualmente, a un número significativo de mujeres en la industria manufacturera (textiles, ropa, bonetería, zapatos, papel y química) y en servicios (comercio, administración pública y labores domésticas). En cambio, en Jalisco no se establecieron las grandes fábricas textiles y modernas como en Puebla y Veracruz, pero contó con industrias pequeñas más diversificadas y con tecnología tradicional, por ejemplo, las de alimentos, ropa, calcetines y calzado (en fábricas y en talleres domiciliarios); además, desde la época colonial ha ofrecido servicios educativos y comerciales a todo el occidente de México. En especial, en la década de 1930 fue el capital comercial el que invirtió considerablemente en la pequeña industria o talleres de ropa, bonetería y de zapatos (Aldana Rendón, 1979, 1980; Arias, 1983, 1985a, 1985b, 1998; Lailson Zorrilla, 1985). Esta inversión posteriormente impulsaría al sector industrial que se dio en la década de 1950.

El movimiento de acción social católico y la Cristiada han recobrado mucha importancia en los últimos años. Estos tópicos se han examinado desde diversos ángulos como la política anticlerical, el movimiento obrero católico, las acciones militares durante la Cristiada y el sinarquismo (Barbosa Guzmán, 1988; Boylan, 2001; Curley, 2001; González, 2000; Ortoll, 1987; Vaca, 1982). Se ha reflexionado sobre las relaciones Iglesia-Estado desde las perspectivas locales, regionales, nacionales e internacionales.

El AHJ alberga documentación que contradice la imagen de las mujeres de Jalisco y Guadalajara como "mujeres beatas pasivas". La participación política de las mujeres en la organización de instituciones de beneficencia y educativas y en la creación de sindicatos y en el movimiento obrero organizado es muy rica. Se ha mostrado la coexistencia de dos tradiciones culturales (la católica y la liberal), que han movilizado a hombres y mujeres en la defensa de sus derechos (Gabayet, 1987; Keremetsis, 1984a, 1984b, 1997). Sobre salud pública se ha descrito el establecimiento de hospitales, la política sanitaria y de higiene, y la práctica médica (Oliver, 1986, 1992a, 1992b, 2003). Finalmente, la historia política del siglo XIX y prin- cipios del XX ha sido objeto de estudio preferencial (Acosta Rico y Vega Castillo, 2006; Aldana Rendón, 1987; AHJ, 2002-2006; Murià, 1980b; Tamayo Rodríguez, 1983, 1988a; Aldana Rendón, 1988a; Romero, 1988, vol. 5; Aldana Rendón, 1988b; Tamayo Rodríguez y Aldana Rendón, 1981; Tamayo Rodríguez y Romero, 1983). También han sido abordadas las divisiones territoriales para reconstruir las vigentes disputas con las entidades colindantes (Murià, 1976).

Como ya indiqué, los avances más importantes cristalizaron en las obras colectivas Historia de Jalisco (1982) y Jalisco desde la revolución (1987). Esta última colección ilustra la ayuda que fueron los instrumentos de consulta elaborados hasta la década de 1930. Sin embargo, la falta de éstos después de 1940 dificultó el avance del conocimiento histórico para los volúmenes dedicados a los decenios de 1940 a 1980, en especial a los referidos a la educación, política, industria y comercio (Acosta, 1988; Luna Zamora et al., 1988; Plascencia Vázquez et al., 1988; Sánchez Susarrey y Medina Sánchez, 1987; Torres Montes de Oca, 1988). Debido a que no hay índices sobre las décadas de 1940 en adelante no se ha profundizado sobre la configuración del movimiento obrero, el Programa Bracero, el debate en torno al sufragio femenino y la industria maquiladora, sólo por citar algunos ejemplos.

\section{LA LEGISLACIÓN EN TORNO A LOS ARCHIVOS}

EL AHJ ha tenido tres legislaciones importantes desde 1978, las cuales han regulado y normado su función interna y su relación con otros archivos estatales: el Reglamento del Archivo Histórico de Jalisco (RAHJ) de 1978; la LRADPHEJ de 1998, y la LTIPEJ de 2002 y $2005^{12}$.

Cuando se estableció el AHJ en 1976, sus objetivos fueron integrar el acervo con la documentación histórica de

\footnotetext{
12 "Reglamento del Archivo Histórico de Jalisco", Periódico Oficial El Estado de Jalisco, 19 de diciembre de 1978, tomo CCLXVIII, núm. 11; "Ley que Regula la Administración de Documentos Públicos e Históricos del Estado de Jalisco", Periódico Oficial El Estado de Jalisco, 8 de enero de 1998, tomo CCCXXVII, secc. III, núm. 47; "Ley de Transparencia e Información Pública del Estado de Jalisco", Periódico Oficial El Estado de Jalisco, 6 de enero de 2005, tomo CCCXLIX.
} 
las dependencias oficiales estatales y con adquisiciones y donativos de documentos referentes al estado de Jalisco; custodiar, rescatar, adoptar, incrementar y conservar el patrimonio documental histórico del estado; inventariar, clasificar y catalogar los fondos documentales históricos y bibliográficos; concentrar leyes, decretos y reglamentos promulgados en el estado de Jalisco; editar publicaciones y el Boletín del Archivo Histórico de Jalisco para dar a conocer las actividades del archivo y los estudios y documentos que sean considerados de interés para la historia regional y nacional, y fomentar el quehacer histórico de la entidad.

El reglamento del AHJ de 1978 normaba su organización, funcionamiento y determinaba las relaciones de trabajo al interior de éste. Concibió a todos los documentos "emanados de las dependencias de gobierno en poder del Archivo [que tenían] el carácter de dominio público por pertenecer al patrimonio del Estado de Jalisco"13. Ningún documento podía "ser destruido o enajenado sin el permiso correspondiente de la dirección del Archivo para que dictamine el valor histórico y la con-
El AHJ cuenta con un Archivo de Concentración, que cumple la función de "recibir, alojar, ordenar y clasificar los acervos" de las dependencias del gobierno de Jalisco ${ }^{15}$. Este reglamento limitaba la consulta de los documentos públicos hasta 1938 porque hasta ese año la documentación estaba liberada. Estipuló que para cualquier consulta debían pasar cuarenta años desde su creación. Los documentos protegidos sólo podían ser revisados por los funcionarios del gobierno y el gobernador del estado. El periodo de liberación de los documentos podía extenderse si no lesionaba los intereses y objetivos del estado.

Veinte años después del RAHJ de 1978 se promulgó la LRADPHEJ. Esta ley se propuso después de la alternancia política en la gubernatura en Jalisco en 1995. La nueva administración panista la concibió como una herramienta legislativa para prevenir la destrucción de documentos públicos, como sucedió con la salida del gobierno príís-

\footnotetext{
${ }^{13}$ Reglamento del Archivo Histórico de Jalisco, p. 1.

${ }^{14}$ Loc. cit.

15 Veánse artículos $19^{\circ}, 20^{\circ}$ y $21^{\circ}$, p. 4.
}

ta, el cual no dejó constancia de lo que fue destruido. Sin embargo, estas prácticas aún continúan realizándose. De acuerdo con Susana Pacheco, actual directora del AHJ, la propuesta de esta ley fue elaborada por Lina Rendón, Octavio de la Vega y la misma Pacheco, integrantes de la Asociación de Archivos ${ }^{16}$. Se presentó una iniciativa de esta ley, pero desafortunadamente no se conserva el registro del debate de las comisiones que intervinieron. Esta ley fue más allá de regular y normar el AHJ y plasmó la política pública estatal en torno a los archivos públicos en trámite, generales, de concentración e históricos. Designó al AHJ un papel importante en la organización y conservación de los documentos en la entidad. Señaló la necesidad de instituir el sistema estatal de documentación y archivos públicos. Puntualizó que el AHJ concentra la documentación del Poder Ejecutivo y sus dependencias públicas.

Al igual que en el RAHJ de 1978, se reconoció que toda la documentación generada en las oficinas gubernamentales era parte del patrimonio documental e histórico y que era de interés público. Esta ley aclaró que dicha información no era propiedad de quien la produjo, pero que dicha entidad tenía la responsabilidad de elaborar sus respectivos inventarios. A diferencia del RAHJ de 1978, que liberaba la documentación después de cuarenta años de haber sido creada, esta ley reducía el periodo a quince años, aunque estipulaba que los investigadores podían solicitar el acceso a documentos resguardados cuando su trabajo lo justificara.

Esta ley señaló que los particulares con archivos, bibliotecas y colecciones personales con valor histórico debían custodiarlos y conservarlos, así como notificarle al AHJ su existencia. Dio pauta acerca de cómo debía funcionar el SEDAP para regular, coordinar y dar agilidad al establecimiento y funcionamiento de archivos; establecer políticas y lineamientos en la administración de documentos; propiciar la adquisición, integración, conservación y custodia de documentos, y fijar los criterios generales para homogeneizar la administración. Asimismo, puntualizó las funciones de la comisión dictaminadora

\footnotetext{
${ }^{16}$ Susana Pacheco, entrevistada por la autora, 15 de febrero de 2007, Guadalajara, Jalisco.
} 
de depuración de documentos que carezcan de interés público después de quince años de haber sido dados de baja de los archivos de trámite y remitidos a los archivos generales. Esta comisión debe formarse cada tres años y estar integrada por cinco personas, entre quienes debe siempre participar el titular del AHJ. Al igual que el RAHJ de 1978, prohíbe el comercio y la enajenación de documentos.

La primera LTIPEJ de 2002 no tomó en cuenta la Ley de Archivos (LRADPHEJ). Ambas leyes no concordaban sobre qué información estaba disponible a partir de qué años y qué se podía destruir. Después de su aprobación se alertó de estas anomalías y tuvo que ser abrogada en su totalidad en $2005^{17}$. La segunda LTIPEJ de 2005 sí incorporó algunos de los lineamientos de la LRADPHEJ de 1998. La actual LTIPEJ — de 2005-contiene los mismos objetivos y principios rectores que la LFTAIPG. Define la transparencia como el "conjunto de disposiciones y actos mediante los cuales los sujetos obligados tienen el deber de poner a disposición de las personas solicitantes la información pública que poseen, y dar a conocer, en su caso, el proceso y la toma de decisiones de acuerdo con su competencia, así como las acciones en el ejercicio de sus funciones"18.

Cada una de las dependencias debe crear una unidad de transparencia e información que funge de acuerdo con esta normatividad. Al igual que la LFTAIPG, clasifica la información en tres tipos: de libre acceso, reservada y confidencial. Se concentra primordialmente en la información actual generada y no en la histórica. Desde que entraron en vigor estas disposiciones, los sujetos obligados deben publicar de manera regular la información sobre su marco normativo; su estructura organizativa; su informe anual de actividades, calendario y agenda; sus gastos; su directorio; su remuneración mensual; los criterios de ingreso, promoción y permanencia de servidores públicos; los servicios que ofrece y los manuales y sistemas que precisan los trámites, así como los requisitos $\mathrm{y}$ formatos para los mismos; los inventarios de bienes

17 Rubén Alonso, entrevistado por la autora, $1^{\circ}$ de noviembre de 2007, Guadalajara, Jalisco.

18 Ley de Transparencia, p. 6.

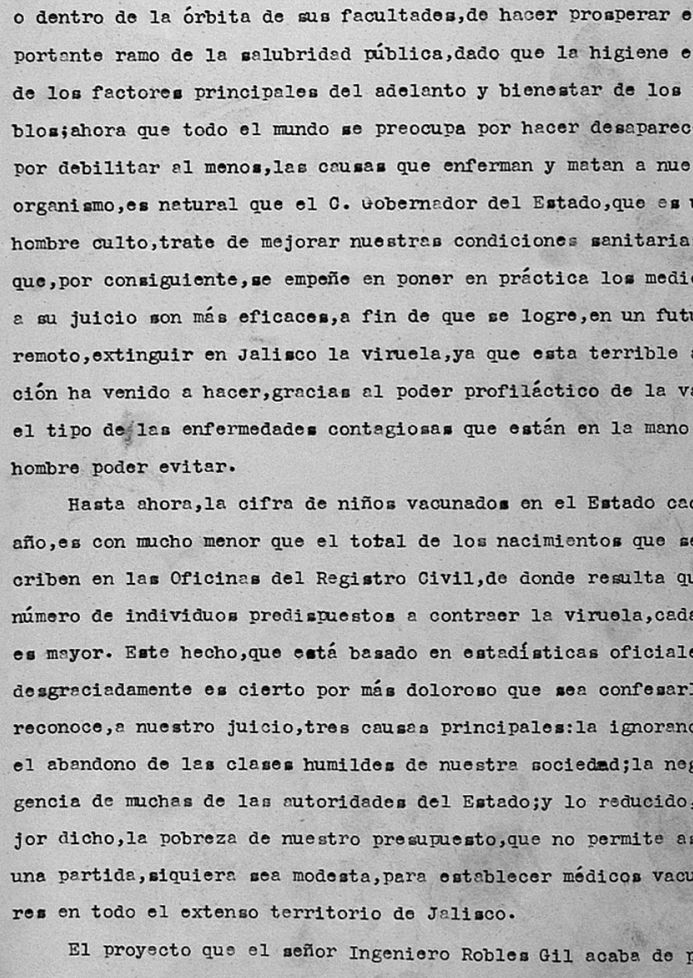

Documento relativo a salubridad pública. AHJ, Ramo de Fomento, F-13-906 JAL/876.

inmuebles y vehículos; los convenios celebrados; los programas operativos, entre otros. Especifica qué deben dar a conocer los poderes legislativo, judicial, ayuntamientos y partidos políticos.

La información reservada es aquella "cuya revelación puede causar un daño o perjuicio irreparable al Estado, por tratarse de información estratégica en materia de seguridad del Estado, seguridad pública o prevención del delito" ${ }^{19}$. Este tipo de documentos recibirá esta clasificación sólo por diez años. La información confidencial debe proteger los datos personales e incluye expedientes con carácter de secretos. Estos documentos son intransferibles e indelegables y conservan este carácter de manera indefinida, pero esto es muy ambiguo.

\footnotetext{
${ }^{19}$ Ley de Transparencia, p. 13
} 


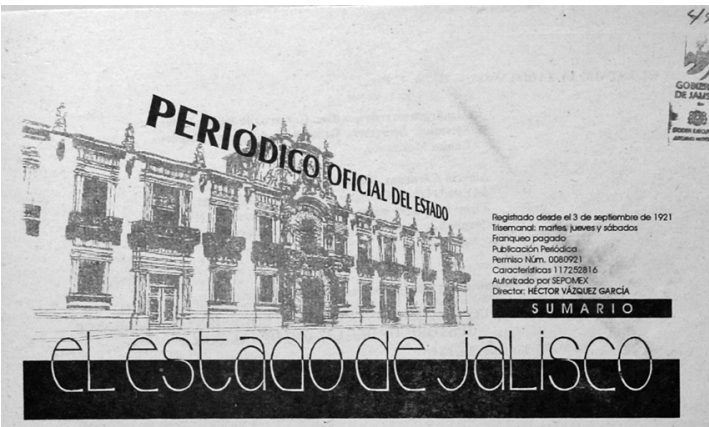

TOMO CCCXXVII GUADALAJARA, JAL. JUEVES 8 DE ENERO DE 1998 SECC. III No. 47

GOBIERNO DEL ESTADO SECRETARÍA GENERAL DE GOBIERNO

DECRETO 17032. Ley que regula la Administración de documentos Públicons e Historicos del Estad

de Jalisco.

Pag.

Periódico oficial El Estado de Jalisco, decreto 17032. Ley que regula la Administración de Documentos Públicos e Históricos del Estado de Jalisco, 8 de enero de 1998.

La LTIPEJ reformó y derogó algunos artículos de la LRADPHEJ de 1998. Derogó el artículo II referente a la determinación de la creación, reproducción, conservación, restauración y eliminación de documentos públicos de carácter oficial e histórico. Asimismo, eliminó el artículo que estipulaba un trato diferenciado para el acceso a la información a investigadores y periodistas. Se ajustó a la Ley del Equilibrio Ecológico y la Protección al Medio Ambiente del Estado de Jalisco ${ }^{20}$. De acuerdo con Rubén Alonso, esta ley fue de las primeras legislaciones que estipularon el derecho a la información ecológica; bastaba con especificar para qué se requería dicha información y

${ }^{20}$ Esta Ley fue publicada en el Periódico Oficial El Estado de Jalisco el 6 de junio de 1989; entró en vigor el 7 de junio de 1989. ya no era necesario puntualizar el interés jurídico ${ }^{21}$. Este punto fue un gran avance y lo retomó la LTIPEJ. Sin embargo, la nueva LTIPEJ afectó el liderazgo y el papel rector del AHJ que le otorgaban el RAHJ de 1978, la LRADPHEJ de 1998 y el SEDAP de 2005. Puntualizó que "los poderes públicos del Estado, los municipios y las dependencias de la administración pública, en el manejo de los documentos administrativos e históricos que tengan bajo su custodia, se sujetarán a lo establecido por la presente ley”22. Sin embargo, no tomó en cuenta los diversos tipos de archivos; solamente clasificó la información en pública, reservada y confidencial. En general, consideró todos los documentos públicos que deben ser de libre acceso. Los documentos reservados "no serán sometidos al proceso de depuración hasta que finalice el plazo de reserva, de acuerdo con las disposiciones de la ley anterior" 23 .

Esta ley derogó las restricciones para consultar la información pública. No obstante, no tomó en cuenta cómo conservar los archivos. Ni en la LRADPHEJ ni en la LTIPEJ quedó claro qué información puede ser depurada. Tampoco cómo pueden coordinarse las unidades de transparencia, el Instituto de Transparencia de la Información Pública de Jalisco (ITIPJ) y el SEDAP.

\section{CONSIDERACIONES FINALES}

Aunque la LTIPEJ logró un gran avance al estipular el acceso a la información, transparentar la gestión pública, garantizar la protección de los datos personales, favorecer la rendición de cuentas y mejorar la organización, clasificación y manejo de documentos, no logró compaginarse con la política de rescate y conservación de archivos, especialmente los históricos. El caso del AHJ muestra que en Jalisco sí ha habido una política de rescate y conservación de los acervos documentales, pero ésta no ha sido suficiente para avanzar en la elaboración de índices, inventarios y catálogos de la documentación pública.

${ }^{21}$ Rubén Alonso, entrevistado por la autora, $1^{\circ}$ de noviembre de 2007,

Guadalajara, Jalisco

${ }^{22}$ Ley de Transparencia, p. 37.

${ }^{23}$ Loc. cit. 
Si se examina la LTIPEJ desde las necesidades y problemas que enfrenta el AHJ se puede señalar que tanto la LFTAIPG como la LTIPEJ no promueven estabilidad laboral para que haya continuidad en la elaboración de los instrumentos de consulta. Desde que se creó el AHJ, en 1978 y hasta la fecha, ha padecido de un gran movimiento del personal; su perfil ha variado y ha dependido del énfasis que le dé el director en turno a cierta carrera profesional. Los sueldos han sido muy bajos y más en los últimos años. Sólo una minoría ha recibido capacitación. Los recursos materiales son muy pocos y las computadoras con que cuentan son obsoletas. Estas condiciones no facilitan la digitalización de la información, los índices, inventarios y catálogos.

Desde la perspectiva de los archivos históricos se podría recomendar que el ITIPJ y el SEDAP trabajen conjuntamente en la elaboración de los lineamientos para el manejo y organización de diferentes archivos: históricos, de concentración, de trámite, electrónicos, visuales y orales. Éstos son vacíos importantes en la organización, conservación y acceso a la información pública. Aunque la LFTAIPG y la LTIPEJ sí buscaron mejorar este aspecto, no se especificaron los pasos, medios y sistema que facilitaran la organización de la información. Es necesario que el ITIPJ y el SEDAP hagan un diagnóstico de dos problemas fundamentales: los archivos de trámite y los históricos, para que en la práctica sí se acelere y facilite la información pública. En el caso de los primeros, se deben conocer las dificultades que enfrenta la administración actual en su gestión para resolver las demandas y problemas sociales. Ya se sabe que los archivos históricos cargan con un retraso significativo en la elaboración de índices, inventarios y catálogos que faciliten su consulta para cualquier ciudadano, como lo ilustra el caso del AHJ. La LTIPEJ no ayuda a resolver este rezago. Este diagnóstico sería la base para contar con un panorama general y detallar puntualmente los reglamentos para la clasificación, manejo, conservación, transferencia y depuración de la información generada en el gobierno del estado en diferentes formatos y soportes. A partir de esto se podría definir con más detalle qué es la información pública reservada y confidencial para especificar cómo será su manejo al interior de las diferentes dependencias gubernamentales, sin olvidar la perspectiva histórica, para que futuras generaciones estudien, investiguen e interpreten nuestro pasado. Por lo tanto, es necesario desarrollar una conciencia a propósito de la importancia en la gestión y administración a corto, mediano y largo plazo, así como de la situación de los diferentes tipos de archivos, la información que generan y los formatos en que fueron creados. Asimismo, es imprescindible mejorar las condiciones de trabajo al interior de los archivos para que se valore la importancia de los acervos públicos y facilitar realmente el acceso a la información y democratizar la sociedad mexicana.

\section{Bibliografía}

Acosta Rico, Fabián y Rogelio Vega Castillo, 2006, Jalisco. Bitácora de un Estado, 1530-1992, 3 vols., Gobierno de Jalisco, Guadalajara.

Acosta, Salvador (ed.), 1988, La expansión educativa, 19401985. La Universidad de Guadalajara y la educación superior, vol. XI de Mario A. Aldana Rendón (coord.), Jalisco desde la revolución, 14 vols., Universidad de Guadalajara, Gobierno del Estado de Jalisco, Guadalajara.

Alba Vega, Carlos, 1980, "Presentación. Del artesanado a la industria manufacturera”, Boletín del Archivo Histórico de Jalisco, vol. IV, núm. 1, pp. 1-12.

Aldana Rendón, Mario Alfonso, 1979, Desarrollo económico de Jalisco, 1821-1940, Universidad de Guadalajara, Guadalajara.

_ 1980 , "La industria textil en Jalisco durante la transición al capitalismo, 1840-1877”, Boletín del Archivo Histórico de Jalisco, vol. IV, núm. 1, pp. 7-16.

__, 1983, "Presentación", Boletín del Archivo Histórico de Jalisco, segunda época, vol. 1, núm. 1, pp.1-2.

- (coord.), 1987, Jalisco desde la revolución, 12 vols, Gobierno del Estado de Jalisco, Universidad de Guadalajara, Guadalajara.

- (coord), 1988a, Jalisco desde la revolución, Guadalajara, vol. 2, 14 vols., Gobierno del Estado de Jalisco, Universidad de Guadalajara, Guadalajara.

— (coord), 1988b, Jalisco desde la revolución, Guadalajara, vol. 5, 14 vols., Gobierno del Estado de Jalisco, Universidad de Guadalajara, Guadalajara.

Anderson, Rodney, 1981, "Documentos de los inarticulados: los cargadores", Boletín del Archivo Histórico de Jalisco, vol. V, núm. 1, pp. 3-5.

AGN (Archivo General de la Nación), 1997, Norma interna- 
cional general de descripción archivística, ISAD (G), Archivo General de la Nación, México.

AHJ (Archivo Histórico de Jalisco), 1979a, Folleto de información y difusión del Archivo Histórico de Jalisco, Universidad Nacional de Educación a Distancia, Guadalajara.

_ 1979 b, Guía de los archivos históricos de Guadalajara, Universidad Nacional de Educación a Distancia, Guadalajara.

_ 1980, Manual de procesos técnicos, Archivo Histórico de Jalisco, Guadalajara.

— 1981, Catálogo de la exposición bibliográfica de Jalisco, 1970-1981, Archivo Histórico de Jalisco, Museo Regional de Guadalajara, Guadalajara.

— 2002-2006, Apuntes históricos. Memoria y cultura de los municipios, Gobierno de Jalisco, Guadalajara.

__, 2003, Mapoteca. Catálogo del Fondo Nueva Galicia, Gobierno de Jalisco, Guadalajara.

—_, 2005, Mapoteca. Planos del Fondo Cartográfico, Gobierno de Jalisco, Guadalajara.

—_ y SGG (Secretaría General de Gobierno), 1982a, Guía de las memorias e informes oficiales de los gobernadores de Jalisco, Universidad Nacional de Educación a Distancia, Guadalajara.

— y SGG (Secretaría General de Gobierno), 1982b, Organización municipal del estado de Jalisco, Universidad Nacional de Educación a Distancia, Guadalajara.

Arias, Patricia, 1983, Fuentes para el estudio de la industrialización en Jalisco, Centro de Investigaciones y Estudios Superiores en Antropología Social, México.

__ 1985a, "La industria en perspectiva”, en Patricia Arias (ed.), Guadalajara, la gran ciudad de la pequeña industria, El Colegio de Michoacán, Zamora, pp. 85-93.

_ 1985 b, "Talleres, comerciantes e industriales: una trilogía persistente”, en Patricia Arias (ed.), Guadalajara, la gran ciudad de la pequeña industria, El Colegio de Michoacán, Zamora, pp. 219-251.

__, 1998, El comercio tapatío, Ágata, México.

Ayala, Silvia, 1994, "Diagnóstico de la educación normal en Jalisco”, en Luz Elena Galván Lafarga (ed.), Memorias del Primer Simposio de Educación en México, Centro de Investigaciones y Estudios Superiores en Antropología Social, México.

Barbosa Guzmán, Francisco, 1988, La Iglesia y el gobierno civil, vol. 6 de Mario Alfonso Aldana Rendón (coord.), Jalisco desde la revolución, Universidad de Guadalajara, Gobierno del Estado de Jalisco, México.

Boylan, Kristina, 2001, “Mexican Catholic Women's Activism, 1929-1940", tesis de doctorado, Universidad de Oxford, Oxford.

Calvo, Thomas y Jean Meyer (eds.), 1989, Colección de documentos para la historia de Nayarit, 5 vols., Universidad de Guadalajara, Centre d'Études Mexicaines et Centroaméricaines, México.

Cárdenas, Cristina, 1987, Manuel López Cotilla. Insurgencia y educación en Jalisco. 1800-1834, Universidad de Guadalajara, Guadalajara.

—_, 1999, Aventuras y desventuras de la educación superior en Guadalajara durante el siglo XIX, Universidad de Guadalajara, Guadalajara.

Cárdenas Castillo, Cristina y Juan Pío Martínez, 1997, “Apuntes para la formación de profesores durante la segunda mitad del siglo XIX", Educar. Revista de Educación, nueva época, núm. 3, en <http://educar.jalisco.gob.mx/03/ 03Carde. html>.

_ 1981 , "Una circular relativa a la conservación de archivos", Boletín del Archivo Histórico de Jalisco, vol. V, núm. 2, pp. 12-13.

_, 1982 , "Informe del Archivo Histórico de Jalisco de enero de 1977 a septiembre de 1982", Boletín del Archivo Histórico de Jalisco, vol. VI, núm. 3, pp. 16-21.

- (ed.), 1995, Historia social de la Universidad de Guadalajara, Centro de Investigaciones y Estudios Superiores en Antropología Social, Universidad de Guadalajara, Guadalajara.

Colección de decretos, circulares y órdenes de los poderes legislativo y ejecutivo del Estado de Jalisco. Comprende la legislación del Estado desde 14 de septiembre de 1823 a 16 de octubre de 1860, 1874, t. II, tipografía de M. Pérez Lete, Guadalajara.

Colección de decretos, circulares y órdenes de los poderes legislativo y ejecutivo del Estado de Jalisco. Comprende la legislación del Estado desde 14 de septiembre de 1823 a 16 de octubre de 1860, 1874, t. III, tipografía de M. Pérez Lete, Guadalajara.

Curley, Robert, 2001, "Slouching Towards Bethlehem: Catholics and the Political Sphere in Revolutionary México", tesis de doctorado, Universidad de Chicago, Chicago.

Dorantes González, Alma, 1993, El conflicto universitario de Guadalajara, 1933-1937, Secretaría de Cultura, Instituto Nacional de Antropología e Historia, Guadalajara.

Fernández Aceves, María Teresa, 1991, "Mercado de trabajo y condiciones de empleo femenino en Guadalajara, 1920-1940", en Carmen Castañeda (ed.), Vivir en Guadalajara. La ciudad y sus funciones, Ayuntamiento de Guadalajara, Guadalajara, pp. 245-272.

_ 1995 , "Las mujeres graduadas en la Universidad de Guadalajara, 1925-1933”, en Carmen Castañeda (ed.), Historia social de la Universidad de Guadalajara, Universidad de Guadalajara, Centro de Investigaciones y Estudios Superiores en Antropología Social, Guadalajara, pp. 97-122. 
2003, "Once We Were Corn Grinders: Women and Labor in the Tortilla Industry of Guadalajara, 1920-1940", International Labor and Working-Class History, núm. 63, pp. 81-101.

Gabayet, Luisa, 1987, "Intentos de asesinato en contra de María A. Díaz, importante sindicalista”, Encuentro, vol. 4, núm. 3, pp. 117-119.

- 1988, Obreros somos: diferenciación social y formación de la clase obrera en Jalisco, El Colegio de Jalisco, Centro de Investigaciones y Estudios Superiores en Antropología Social, Guadalajara.

García Alcaraz, María Guadalupe, 1993, "Poder, educación y religión. Municipio, gobierno del estado, arzobispado y escuelas primarias en Guadalajara. 1867-1914", tesis de maestría, Instituto de Investigaciones Dr. José María Luis Mora, México.

__ 1997, "Zunismo y escuelas particulares en Jalisco: conflicto y resistencia, 1925-1926”, Educar. Revista de Educación, nueva época, núm. 3, en <http://educar.jalisco. gob.mx/03/03García.html>.

García, Óscar, 1993, La educación superior en el occidente de México. Siglo XX, vol. II, Universidad de Guadalajara, Guadalajara.

- y Sonia Ibarra, 2000, Ochenta años de educación pública federal en Jalisco, vol. I, Sindicato Nacional de Trabajadores de la Educación, México.

Gómez Fregoso, J. Jesús, 1980, "Los orígenes del Sindicato de Panaderos en Guadalajara, 1915-1931, según el Archivo Histórico de Jalisco", Boletín del Archivo Histórico de Jalisco, vol. IV, núm. 2, pp. 2-7.

González, Fabián, 1981, "Presentación. Proletariado y trabajadores de los servicios en Jalisco, 1890-1920", Boletín del Archivo Histórico de Jalisco, vol. V, núm. 1, pp. 1-2.

González, Moisés, 2000, Cristeros y agraristas, 5 vols., El Colegio de México, México.

Guzmán Sánchez, Rafael, 1989, “Una aproximación a la realidad del Archivo Histórico de Jalisco", ponencia presentada en el Foro Nacional de Archivos, México-Distrito Federal.

Keremetsis, Dawn, 1984a, "La doble jornada de la mujer en Guadalajara, 1910-1940”, Encuentro, núm. 1, pp. 41-64.

_ $1984 \mathrm{~b}$, "La industria de empaques y sus trabajadoras: 1910-1940”, Encuentro, vol. 2, núm. 1, pp. 57-63.

__ 1997, "María Arcelia Díaz (1896-1939): Union Leader, Feminist, and Defender of Revolutionary Legislation", ponencia presentada en la Latin American Studies Association, 17 de abril, Guadalajara.

Ladrón de Guevara, Helen, 1977, "Historia del Archivo Histórico de Jalisco", Boletín del Archivo Histórico de Jalisco, vol. I, núm. 1, pp. 29-33.
Lailson Zorilla, Silvia, 1985, "De mercaderes a industriales”, en Patricia Arias (ed.), Guadalajara: la gran ciudad de la pequeña industria, El Colegio de Michoacán, Zamora, pp. 191-218.

Luna Zamora, Rogelio, Cristina Padilla Dieste, Adrián de León Arias y Jesús Arroyo Alejandre (eds.), 1988, Crecimiento industrial y manufacturero, 1940-1980, vol. XIII de Mario A. Aldana Rendón (coord.), Jalisco desde la revolución, 14 vols., Universidad de Guadalajara, Gobierno del Estado de Jalisco, Guadalajara.

Mercado Martínez, Abel, 1986, "Influencias ideológicas de la Universidad de Guadalajara, 1925-1940”, tesis de licenciatura, Universidad de Guadalajara, Guadalajara.

Meyer, Jean, 1989a, El Gran Nayar, Universidad de Guadalajara, Centre d'Études Mexicaines et Centroaméricaines, México.

__ 1989b, La tierra de Manuel Lozada, Universidad de Guadalajara, Centre d'Études Mexicaines et Centroaméricaines, México.

—_ 1990, De cantón de Tepic a estado de Nayarit, Universidad de Guadalajara, Centre d'Études Mexicaines et Centroaméricaines, México.

_ 1997, Breve historia de Nayarit, Fideicomiso Historia de las Américas, El Colegio de México, Fondo de Cultura Económica, México.

Murià, José María, 1976, Historia de las divisiones territoriales de Jalisco, Instituto Nacional de Antropología e Historia, Secretaría de Educación Pública, Centro Regional de Occidente, México.

_ 1980 a, Historia de Jalisco, 4 vols, Gobierno de Jalisco, Guadalajara.

—_, 1980b, Historia de Jalisco. De la primera república centralista a la consolidación del Porfiriato, vol. 3, Gobierno de Jalisco, Guadalajara.

Oliver, Lilia V., 1986, Un verano mortal: análisis demográfico y social de una epidemia de cólera: Guadalajara, 1833 Universidad Nacional de Educación a Distancia, Guadalajara.

_, 1992a, El Hospital Real de San Miguel de Belén, 15811802, Universidad de Guadalajara, Guadalajara.

__, 1992b, Los betlemitas y la construcción de la nueva "fábrica” para el Hospital Real de San Miguel de Belén, Guadalajara, 1787-1794, Universidad de Guadalajara, Guadalajara.

— 2003 , Salud, desarrollo urbano y modernización en Guadalajara, 1797-1908, Universidad de Guadalajara, Guadalajara.

Ortoll, Servando, 1987, "Catholic Organizations in Mexico's National Politics and International Diplomacy", tesis de doctorado, Universidad de Columbia, Columbia. 
Peregrina, Angélica, 1982, "La educación en Jalisco durante el Porfiriato", Boletín del Archivo Histórico de Jalisco, vol. VI, núm. 3, pp. 7-13.

__ 1992, La Escuela Normal de Jalisco en su centenario, 1892-1992, El Colegio de Jalisco, Guadalajara.

, 1993, La educación superior en el occidente de México, 2 vols., Universidad de Guadalajara, El Colegio de Jalisco, Guadalajara.

Plascencia Vázquez, Felipe, Silvia Ayala, Carlos Enrique Orozco y Abel Mercado Martínez (eds.), 1988, La expansión educativa, 1940-1985. Educación primaria, secundaria y media superior, vol. XI, t. I, de Mario A. Aldana Rendón (coord.), Jalisco desde la revolución, 14 vols., Universidad de Guadalajara, Gobierno del Estado de Jalisco, Guadalajara.

Rendón, Lina, 1979, “Archivo Histórico de Jalisco”, en Carmen Castañeda García (ed.), Guía de los archivos históricos de Guadalajara, Universidad Nacional de Educación a Distancia, Guadalajara, pp. 26-32.

Rodríguez García, Rubén, 1983, "Un proyecto de colonización de la Sierra de Alica, 1861-1862", Boletín del Archivo Histórico de Jalisco, segunda época, vol. I, núm. 1, pp.3-6.

Rosas Benítez, Alberto, 1977, "Presentación", Boletín del Archivo Histórico de Jalisco, vol. I, núm. 1, pp. I-II.

Sánchez Susarrey, Jaime e Ignacio Medina Sánchez (eds.), 1987, Historia política, 1940-1975, vol. 9 de Mario Alfonso Aldana Rendón (coord.), Jalisco desde la revolución, 14 vols., Universidad de Guadalajara, Gobierno del Estado de Jalisco, Guadalajara.

Tamayo Rodríguez, Jaime E., 1983, El movimiento agrario y la revolución maderista (Jalisco, 1910-1913). El movimiento agrario y la revolución mexicana: dos momentos cruciales en Jalisco, Centro de Estudios Históricos del Agrarismo en México, Guadalajara.

__, 1985a, La estructura del sindicalismo en Jalisco, Instituto de Estudios Sociales, Universidad de Guadalajara, Guadalajara.

, 1985b, "Movimiento obrero y lucha sindical", en Patricia Arias (ed.), Guadalajara, la gran ciudad de la pequeña industria, El Colegio de Michoacán, Zamora, pp. 131-158.
1987, El movimiento obrero jalisciense y la crisis del '29: la última batalla de los rojos, Instituto de Estudios Sociales, Universidad de Guadalajara, Guadalajara. , 1988a, La conformación del Estado moderno y los conflictos políticos, 1917-1929, vol. 2 de Mario A. Aldana Rendón (coord.), Jalisco desde la revolución, 14 vols., Gobierno del Estado de Jalisco, Universidad de Guadalajara, Guadalajara.

—_, 1988b, Los movimientos sociales, 1917-1929, vol. 5 de Mario A. Aldana Rendón (coord.), Jalisco desde la revolución, 14 vols., Universidad de Guadalajara, Gobierno del Estado de Jalisco, Guadalajara.

— 1988 c, "Los obreros", en Laura Romero (ed.), Movimientos sociales, 1929-1940, vol. 5 de Mario A. Aldana Rendón (coord.), Jalisco desde la revolución, 14 vols., Guadalajara, Universidad de Guadalajara, Gobierno del Estado de Jalisco, pp. 73-97.

— y Mario A. Aldana Rendón, 1981, Del PNR al PRI en Jalisco, Instituto de Estudios Sociales, Universidad de Guadalajara, Guadalajara.

— y Laura Romero, 1983, La rebelión estradista y el movimiento campesino (1923-1924), Centro de Estudios Históricos del Agrarismo en México, Guadalajara.

— y Patricia Valles, 1993, Anarquismo, socialismo y sindicalismo en las regiones, Universidad de Guadalajara, Guadalajara.

Torre, Federico de la, 2000, La ingeniería en Jalisco en el siglo XIX. Génesis y desarrollo de una profesión, Instituto Tecnológico de Estudios Superiores de Occidente, Universidad de Guadalajara, Guadalajara.

Torres Montes de Oca, J. Abelino (ed.), 1988, El comercio y su conformación, 1940-1987, vol. 14 de Mario A. Aldana Rendón (coord.), Jalisco desde la revolución, 14 vols., Universidad de Guadalajara, Gobierno del Estado de Jalisco, Guadalajara.

Vaca, Agustín, 1982, "La política clerical en Jalisco durante el Porfiriato", Boletín del Archivo Histórico de Jalisco, vol. VI, núm. 3, pp. 3-6. 